\title{
CLEAN UP SAMPAH, EDUKASI SAMPAH DAN PEMBENTUKAN BANK SAMPAH DI SDI BHOANAWA 1 KELURAHAN RUKUN LIMA KABUPATEN ENDE
}

\author{
Ariswan Usman Aje 1), Hamsa Doa'), Hasti Sulaiman ${ }^{3)}$, Lely Suryani 1), Maria Goretty D. Bantas ${ }^{1)}$ \\ 1)Program Studi Pendidikan Matematika, FKIP, Universitas Flores, Ende, NTT, Indonesia \\ 2) Program Studi Pendidikan Fisika, FKIP, Universitas Flores, Ende, NTT, Indonesia \\ ${ }^{3)}$ Program Studi Pendidikan Sejarah, FKIP, Universitas Flores, Ende, NTT, Indonesia \\ Corresponding author: Ariswan Usman Aje \\ E-mail : ariswanusman@gmail.com
}

Diterima 30 November 2021, Direvisi 01 Desember 2021, Disetujui 01 Desember 2021

\begin{abstract}
ABSTRAK
SDI Bhoanawa 1 adalah mitra dalam Program Kemitraan Masyarakat yang merupakan sekolah dasar yang berdiri pada tahun 1980. Sekolah ini terletak di tengah-tengah pemukiman warga Bhoanawa Kelurahan Rukun Lima Kabupaten Ende. Masalah sampah tidak lepas dari kehidupan manusia, dimana ada manusia selalu saja ada sampah yang dihasilkan. Sampah disekolah adalah sisa-sisa kegiatan sekolah seperti kertas, plastik bekas, kemasan makanan ringan dan sisa lainnya yang tidak terpakai lagi yang ditemukan disekitar lingkungan sekolah. Sampah-sampah tersebut juga ditemukan dilingkungan sekolah SDI Bhoanawa 1 maupun dilingkungan perumahan sekitar sekolah. Tujuan dari kegiatan ini adalah untuk memberikan edukasi tentang permasalahan sampah dan melakukan aksi langsung dilapangan dengan melakukan clean up sampah dan pembentukan Bank sampah dengan lokasi sasaran di SDI Bhoanawa 1. Pada kegiatan pengabdian ini tim pengabdian juga menggandeng komunitas Anak Cinta Lingkungan Kabupaten Ende (ACIL) Ende. Metode yang digunakan dalam kegiatan ini adalah Metode Sosialisasi, Clean Up, Pembentukan Bank Sampah. Hasil Kegiatan pengabdian ini berjalan dengan baik, hal tersebut terlihat dari antusias siswa SDI Bhoanawa 1 dalam mengikuti rangkaian kegiatan ini. Banyak hal positif yang diperoleh dari kegiatan ini dimana siswa-siswi SDI Bhoanwa 1 mendapatkan materi pengelolaan sampah yang baik. Siswa-siswi SDI Bhoanawa 1 mampu memahami sampah, masalah dan solusi, serta dapat mengambil manfaat dari sampah. Hal tersebut dapat dilihat dari hasil Post Test setelah kegiatan dimana terdapat peningkatan pembamaman siswa akan sampah, masalah dan solusi serta pegelolaan dan pemanfaatannya. Peningkatan tersebut sebesar $80 \%$.
\end{abstract}

Kata kunci: clean up Sampah; edukasi sampah; pembentukan bank sampah.

\begin{abstract}
SDI Bhoanawa 1 is a partner in the Community Partnership Program which is an elementary school that was founded in 1980. This school is located in the middle of the residential area of Bhoanawa residents, Rukun Lima Village, Ende Regency. The problem of waste cannot be separated from human life, where there are humans there will always be waste produced. School waste is the remnants of school activities such as paper, used plastic, snack packaging and other unused remnants found around the school environment. The garbage was also found in the SDI Bhoanawa 1 school environment and in the housing environment around the school. The purpose of this activity is to provide education about waste problems and take direct action in the field by cleaning up waste and establishing a waste bank with a target location at SDI Bhoanawa 1. In this service activity the community service team also cooperates with the Anak Cinta Lingkungan community in Ende Regency (ACIL). Ende. The method used in this activity is the Method of Socialization, Clean Up, Establishment of a Waste Bank. The results of this service activity went well, it was seen from the enthusiasm of SDI Bhoanawa 1 students in participating in this series of activities. Many positive things were obtained from this activity where the students of SDI Bhoanwa 1 received good waste management materials. The students of SDI Bhoanawa 1 are able to understand waste, problems and solutions, and can take advantage of waste. This can be seen from the results of the Post Test after the activity where there is an increase in students' understanding of waste, problems and solutions as well as management and utilization. The increase is $80 \%$
\end{abstract}

Keywords: garbage clean up; waste education; the establishment of a garbage bank. 


\section{PENDAHULUAN}

SDI Bhoanawa 1 merupakan sebuah sekolah dasar yang berdiri pada tahun 1980 . Sekolah ini terletak di tengah-tengah pemukiman warga Bhoanawa kelurahan Rukun Lima kabupaten Ende. Sejak berdirinya sekolah ini telah menghasilkan banyak lulusan, dengan profil lulusan yang beraneka ragam baik sebagai guru, TNI/Polri dan lain sebagainya. Beralamat di jalan R.W.Monginsidi sekolah ini merupakan tujuan sekolah bagi anak-anak dilingkungan sekitarnya. Sebagai sekolah yang terletak di tengah-tengah pemukiman warga, sekolah ini diharapkan dapat dijadikan contoh bagi lingkungan sekitar. Contoh tersebut dapat dilihat dari tampak sekolah seperti kebersihan dan keasrian lingkungannya. Agar dapat menjadi contoh dimasyarakat SDI Bhoanawa 1 senantiasa berupaya memperbaiki diri, salah satunya dengan menjadi contoh dalam menangani permasalahan sampah dilingkungan sekitar.

Masalah sampah tidak lepas dari kehidupan manusia, dimana ada manuasia selalu saja ada sampah yang dihasilkan. Disekitar kita tidak sulit menemukan sampah yang berserakan, tak terurus dan tak tahu manfaat yang dapat diberikan sampah selain dari anggapan bahwa sampah adalah barang bekas yang tidak dipakai lagi. Menurut UU Republik Indonesia Nomor 18 Tahun 2008 (Suryani et al., 2019)Tentang Pengelolaan sampah, sampah adalah sisa-sisa kegiatan sehari hari manusia yang berbentuk padat sedangkan menurut Manik (Hadi et al., 2017) mendefenisikan sampah sebagai suatu benda yang tidak digunakan atau tidak dikehendaki dan harus dibuang, yang dihasilkan oleh kegiatan manusia.

Permasalahan sampah tidak hanya terjadi di lingkungan masyarakat, di instansi pemerintahpun tidak dapat terhindar dari masalah ini. Salah satu contoh permasalahan sampah terdapat di disekolah. Sampah disekolah adalah sisa-sisa kegiatan sekolah seperti kertas, plastik bekas, kemasan makanan ringan dan sisa lainnya yang tidak terpakai lagi yang ditemukan disekitar lingkungan sekolah. Sampah-sampah tersebut juga ditemukan dilingkungan sekolah SDI Bhoanawa 1 maupun dilingkungan perumahan sekitar sekolah. Banyaknya sampah yang berserakan menyebabkan turunnya kualitas lingkungan. Menurut Barry (Usman Aje et al., 2020) Salah satu hubungan antara penurunan kualitas lingkungan hidup dan manusia (sosial) yaitu sebagian besar penurunan kualitas lingkungan hidup hasil dari tindakan atau perilaku manusia. Maka dengan demikian agar kualitas lingkungan tetap baik maka perlu adanya perilaku manusia untuk sadar dalam menjaga kualitas lingkungan agar tetap sehat serta kreatif dan inovatif dalam menangani persoalan sampah.

Sebagai sekolah yang menjadi contoh dilingkungan masyarakat, SDI Bhoanawa 1 juga akan berusa mengatasi persolan sampah dengan terlbih dahulu dimulai dari lingkungan sekolah. Dengan memperhatikan kondisi SDI Bhoanawa 1 tersebut tim pengabdian mencoba memberikan solusi terkait penanganan masalah sampah. Adapun solusi dalam mengatasi permasalahan sampah yang kami tawarkan dalam kegiatan pengabdian ini adalah dengan memberikan edukasi tentang sampah dan permasalahannya. Pada kegiatan ini selain edukasi kami juga melakukan aksi langsung dilapangan dengan melakukan clean up sampah dan pembentukan Bank sampah dengan lokasi sasaran di SDI Bhoanawa 1 dan. Edukasi yang kami lakukan sebagai bagian dari penanaman karakter cinta lingkungan pada anak. Program yang kami pilih ini juga merupakan bagian dari penanaman karakter cinta lingkungan. Dengan karakter cinta lingkungan yang dimiliki kelak anak akan bersungguh sungguh dalam menangani permasalahan sampah dengan baik dan tepat guna.

Upaya menangani permasalahan sampah tidak hanya dengan cara membuang sampah pada tempatnya tetapi bagaimana mengelolah sampah dengan baik. Pengelolaan sampah dapat dilakukan salah satunya dengan cara 3R yakni reuse, reduse, recycle. Untuk mempermudah proses daur ulang dan pemanfaatan ulang, langkah-langkah yang dilakukan adalah pemisahan, penyimpanan, limbah pengiriman atau penjualan (Suryani et al., 2019). Pada Prosesnya kegiatan pengelolalaan sampah yang dilakukan di SDI Bhoanawa 1 adalah dengan membentuk Bank Sampah. Pembentukan bank sampah di SDI Bhonawa 1 sebagai pilihan kreatif dan inovatif dalam mengatasi permasalahan sampah disekolah tersebut. Selain itu dengan bank sampah tersebut maka kenginan sekolah untuk menjadi contoh dilingkungan masyarakat dapat terwujud.

Pada kegiatan pengabdian ini tim pengabdian juga menggandeng komunitas Anak Cinta Lingkungan Kabupaten Ende (ACIL) Ende. Sebagai komunitas yang bergerak dibidang lingkungan ACIL telah memiliki Bank Sampah. Bank sampah ACIL ini akan menjadi contoh dalam membentuk bank sampah SDI Bhoanawa1. Bank sampah yang dibentuk nantinya diharapkan dapat memberikan 
manfaat baik untuk siswa SDI Bhoanawa 1 maupun masyarakat lingkungan sekitar. Dengan adanya Bank sampah akan maka dapat dijadikan sebagai peluang usaha, menghasilkan dan menyerap tenaga kerja dengan catatan usaha tersebut dikelola dengan manajemen yang baik. Salah satu model pengelolaan sampah adalah dengan bank sampah (Lestari \& Riyanto, 2018). Pada akhirnya Diharapkan kegiatan ini dapat menjawab persoalan sampah yang ada dilingkungan sekitar khususnya di SD Bhoanawa 1 dan dapat mewujudkan tujuan sekolah sebagai contoh dalam penanganan masalah sampah dilingkungan masyarakat. Selain itu kegiatan ini juga merupakan wujud dari Pendidikan karakter bagi siswa-siswi SDI Bhoanawa 1, khususnya karakter cinta lingkungan. Sebagai mana yang disampaikan Wibowo (Wahjusaputri et al., 2019), Pendidikan karakter adalah Gerakan nasional menciptakan sekolah yang mendorong kaum muda yang etis (mempunyai tata krama/sopan santun), bertanggung jawab, dan peduli dengan memberikan contoh (model) dan mengajarkan karakter yang baik melalui penekanan pada nilai universal.

\section{METODE}

Kegiatan pengabdian ini dilaksanakan di sekolah SDI Bhoanawa 1 Kelurahan Rukun Lima Kecamatan Ende Selatan Kabupaten Ende. Waktu pelaksanaan kegiatan ini selama dua bulan, yang dilakukan pada bulan Mei dan Juni 2021. Subjek dalam pengabdian ini adalah sebanyak 30 siswa-siswi SDI Bhoanawa 1. Adapun metode yang digunakan dalam penelitian ini adalah :

1. Metode Sosialisasi

Metode sosialisasi digunakan untuk menyampaikan tujuan kegiatan sekaligus pencerahan dengan memberikan sosialisasi materi sampah, masalah dan solusi. Sasaran sosialisasi ini adalah siswa-siswi SDI Bhoanawa 1.

2. Clean Up

Clean Up merupakan rangkaian kegiatan praktik langsung pilih dan pilah sampah. Kegiatan Clean Up dilakukan dilingkungan sekolah SDI Bhoanawa 1.

3. Pembentukan Bank Sampah

Pembentukan Bank Sampah SDI Bhoanawa 1 merupakan muara dari kegiatan pengabdian ini, dalam menjawab persoalan penanganan sampah di SDI Bhionawa 1 Ende.

\section{HASIL DAN PEMBAHASAN}

Awal kegiatan ini dilakukan dengan observasi ke sekolah sasaran untuk mengetahui masalah dan kebutuhan sekolah khususnya dalam mengatasi persoalan sampah disekolah. Adapun kegiatan yang dilakukan dalam pengabdian ini adalah sebagai berikut:

\section{Sosialisasi (Edukasi Sampah)}

Kegiatan Sosialisasi ini kami lakukan bekerjasama dengan kelompok ACIL (Anak Cinta Lingkungan) Kabupaten Ende. Sebelum melakukan kegiatan sosialisasi (Edukasi Sampah) kegiatan terlebih dahulu dengan membagikan pre test ( tes awal) kepada siswa tentang pengetahuan sampah yang mereka miliki. Pre test (tes awal) ini untuk mengukur dan melihat seberapa jauh pemahaman siswa SDI Bhoanawa 1 tentang sampah. Materi Edukasi yang diberikan adalah Sampah, Masalah dan Solusi. Kegiatan tersebut dihadiri siswa siswi beserta guru-guru SDI Bhoanawa 1 dan juga para guru. Diakhir kegiatan siswasiswi SDI Bhoanwa 1 diberikan post test (tes akhir). Post test tersebut dimaksudkan untuk mengukur tingkat pemahaman siswa setelah mendapatkan materi tentang sampah masalah dan solusi.

Berdasarkan hasil PreTest (Tes awal) yang diberikan dari 30 siswa SDI Bhoanawa 1 yang mengikuti kegiatan tersebut $80 \%$ atau 24 siswa masih belum memahami tentang sampah, pengelolaan dan manfaat yang dapat diambil. Setelah melakukan sosialisasi pemberian materi mengenai sampah masalah dan solusi, selanjutnya tim memberikan tes akhir. Dari hasil post test (Tes akhir), dari 30 siswa atau 100\% yang mengikuti kegiatan sosialisasi semuanya dapat memahami bagaimana sampah, pengelolaan dan manfaat yang dapat diambil.

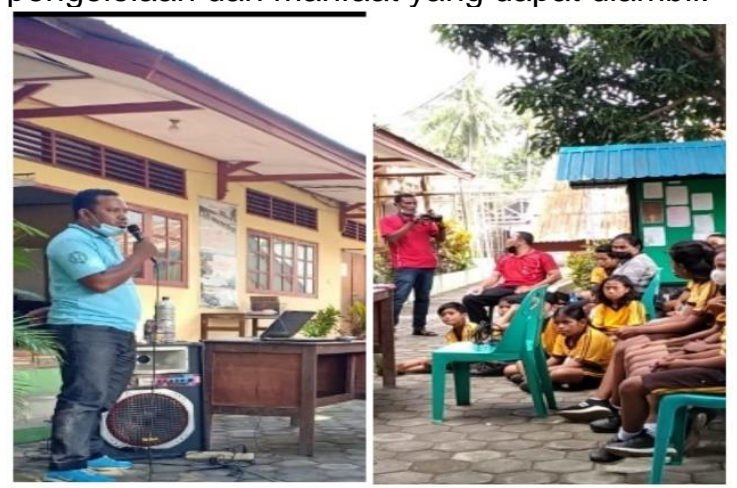

Gambar 1. Sosialiasai Edukasi Sampah, Masalah dan Solusi

(Sumber : Dokumentasi Pribadi ).

\section{Clean Up Sampah dan Pemilahan Sampah}

Kegiatan Clean Up sampah dilakukan pada bulan juni 2021. Kegiatan ini dilakukan bersama siswa-siswi SDI Bhoanawa 1, Tim Pengabdian, ACIL Ende dan Para Guru SDI Bhoanawa 1. Kegiatan Clean Up sampah 
terbatas di sekitar lingkungan sekolah SDI Bhoanawa 1. Kegiatan Clean up sampah dilakukan selama kurang lebih 2 jam. Selanjutnya sampah yang berhasil dipungut kemudian dipilah berdasarkan jenisnya.

Pemimilahan sampah dilakukan dilapangan sekolah yang dilakukan oleh siswasiswi SDI Bhoanawa 1 Ende. Pemilahan sampah menjadi 2 jenis yakni sampah organik dan an organik. Pemilahan sampah ini sekaligus praktik langsung dari teori yang sudah di dapat siswa-siswi pada kegiatan tahap 1 yakni pada kegiatan edukasi sampah. Pada kegiatan Clean Up sampah ini kita dapat melihat sejauh mana siswa-siswi SDI Bhonawa 1 Ende memahami jenis sampah dan bagaimana sampah tersebut dipilih dan di pilah. Dengan langsung terjun ke lapangan dalam wujud ikut terlibat dalam membersihkan lingkungan sekolah maka disini kita dapat melihat karakter cinta lingkungan yang tampak dari anak-anak SDI Bhoanwa 1 Ende. Karakter cinta lingkungan tersebut akan nampak dari sikap siswa-siswi yang terlibat pada kegiatan clean up sampah tersebut. Pada kegiatan ini juga dapat dilihat bahwa siswa-siswi SDI Bhoanawa 1 dapat memilah sampah berdasarkan jenisnya.

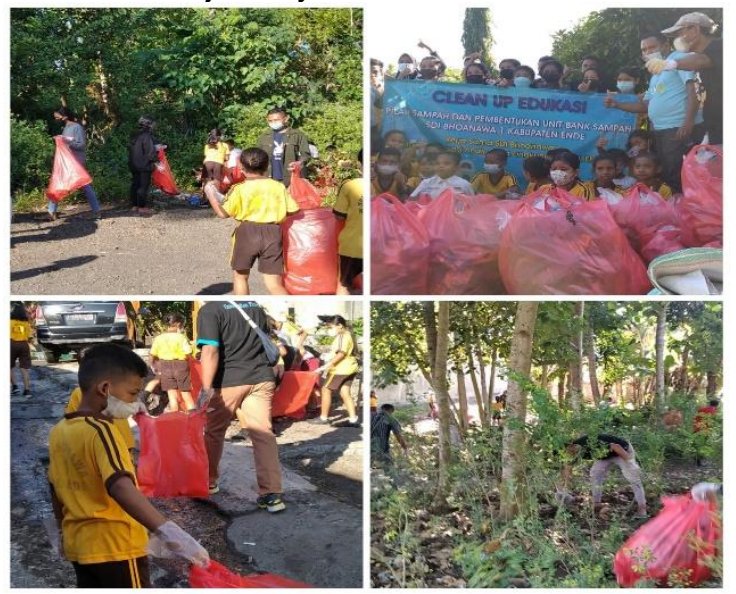

Gambar 2. Kegiatan Clean Up sampah di sekitar sekolah SDI Bhoanawa 1 Ende (Sumber : Dokumentasi Pribadi ).

\section{Pembentukan Bank Sampah SDI Bhoanawa 1 \\ Sebagai Muara dari kegiatan} pengabdian ini adalah terbentuknya Bank Sampah di SDI Bhoanwa 1 Ende. Keberadaan Bank sampah di SDI Bhoanawa 1 sebagai wujud dari kebersihan lingkungan dan manajemen pengelolaan sampah secara baik dan benar. Kegiatan pembentukan Bank Sampah ini dilakukan agar siswa-siswa juga dapat mengambil bagian dan peran masingmasing dalam pengelolaan sampah di sekolah. Selain itu dengan adanya manajemen Bank Sampah siswa-siswa juga dilatih berorganisasi.
Dengan Bank sampah maka dari sisi ekonomi siswa-siswi dapat memanfaatkan sampah untuk menghasilkan uang. Selain itu sampah juga dapat dikelola menjadi barang-barang yang berguna.

Pada Akhirnya kegiatan pembentukan Bank Sampah ini dapat dilaksanakan dengan baik. Manajemen Bank sampah SDI Bhoanawa 1 dapat dibentuk dengan struktur kepengurusan sebagai berikut ; Kepala Sekolah SDI Bhoanawa 1 sebagai pelindung, Ketua Komite Sekolah sebagai Penasihat, Wali Kelas 4 sebagai unit Tabung dan Siswa -siswi sebagai unit Daur Ulang. Untuk anggotanya adalah semua siswa SDI Bhoanawa 1 Ende. Nama manajemen pengelolaan sampah tersebut adalah "GELISAH" Gerakan Lingkungan Sehat.

\section{SIMPULAN DAN SARAN}

Kesimpulan yang dapat diambil dalam pelaksanaan kegiatan pengabdian ini adalah : a) Kegiatan pengabdian ini berjalan dengan baik, hal tersebut terlihat dari antusias siswa SDI Bhoanawa 1 dalam mengikuti rangkaian kegiatan ini, b) Banyak hal positif yang diperoleh dari kegiatan ini dimana siswa-siswi SDI Bhoanwa 1 mendapatkan materi pengelolaan sampah yang baik. Siswa-siswi SDI Bhoanawa 1 mampu memahami sampah, masalah dan solusi, serta dapat mengambil manfaat dari sampah. Hal tersebut dapat dilihat dari hasil Post Test setelah kegiatan dimana terdapat peningkatan pembamaman siswa akan sampah, masalah dan solusi serta pegelolaan dan pemanfaatannya. Peningkatan tersebut sebesar $80 \%$, c) Siswa SDI Bhoanawa 1 mampu menterjemahkan pengetahuan menjaga kebersihan lingkungan dengan terlibat langsung dalam kegiatan Clean Up sampah di Lingkungan sekolah, d) Siswa-siswi SDI bhoanawa 1 mampu membedakan jenis sampah dengan baik. Hal tersebut dapat terlihat dari proses pilih dan pilah sampah yang dilakukan siswa-siswi tersebut, e) Unit Bank sampah SDI Bhoanawa 1 dengan nama "GELISAH" dapat dibentuk dengan keterlibatan semua warga SDI Bhoanawa 1, f) Kegiatan pengabdian ini dapat meminimalisir pencemaran lingkungan sekitar, khusnya masalah sampah dengan adanya Bank Sampah SDI Bhoanawa 1.

\section{UCAPAN TERIMAKASIH}

Pada akhirnya penulis ingin mengucapkan terimakasih kepada berbagai pihak yang telah bekerja sama dalam mensukseskan terselenggaranya pengabdian ini. Ucapan terimakasih ini kami haturkan kepada mitra kami Kepala Sekolah, Guru-guru 
dan siswa-siswi SDI Bhoanawa 1 Ende. Kami juga mengucapkan terimakasih kepada organisasi anak cinta lingkungan kabupaten Ende (ACIL). Atas dukungan dan keterlibatannya maka kegiatan pengabdian ini dapat dilaksanakan dengan baik.

\section{DAFTAR RUJUKAN}

Hadi, M. F., Darwin, R., Widiarsih, D., Hidayat, M., Murialti, N., \& Asnawi, M. (2017). Pemanfaatan Barang-Barang Bekas Yang Bernilai Ekonomi Bagi Peningkatan Produktivitas Jiwa Entrepreneur lbu Rumah Tangga Rt.01/Rw.12 Desa Limbungan Kecamatan Rumbai Pesisir. Jurnal Pengabdian UntukMu NegeRI, 1(2), 42-47.

https://doi.org/10.37859/jpumri.v1i2.23 2

Lestari, N. P., \& Riyanto, D. W. U. (2018). IbM Bank Sampah Desa Mojorejo Kota Batu. MATAPPA: Jurnal Pengabdian Kepada Masyarakat, 1(1), 23. https://doi.org/10.31100/matappa.v1i1. 97

Suryani, L., Aje, A. U., Tute, K. J., Flores, U., Studi, P., Informatika, S., Teknologi, F., \& Universitas, I. (2019). KABUPATEN ENDE DALAM PEGELOLAAN LIMBAH ORGANIK DAN ANORGANIK BERBASIS $3 R \quad$ UNTUK MENGESKALASI NILAI. 3(2), 1-8.

Usman Aje, A., Lely Suryani, \& Kristianus J. Tute. (2020). Pemberdayaan Masyarakat Desa Anaraja Dalam Meningkatkan Sdm Melalui Psikoedukasi Dan Pendidikan Lingkungan Berbasis Kearifan Lokal. Amaliah: Jurnal Pengabdian Kepada Masyarakat, 4(1), 23-32. https://doi.org/10.32696/ajpkm.v4i1.35 6

Wahjusaputri, S., Hermanto, S., \& Indah Nastiti, T. (2019). Program Bank Sampah Dengan Model Dem Sebagai Strategi Pendidikan Karakter Bagi Siswa Sdn Kelapa Dua Wetan 06 Pagi Jakarta Timur. Prosiding Kolokium Doktor Dan Seminar Hasil Penelitian Hibah, 1(1), 312-333.

https://doi.org/10.22236/psd/11312-

33381 